\title{
The antimycotic effect of ellagitannins from raspberry (Rubus idaeus L.) on Alternaria alternata ŁOCK 0409
}

\author{
Elżbieta Klewicka ${ }^{1} \cdot$ Michał Sójka $^{2} \cdot$ Sylwia Ścieszka ${ }^{1} \cdot$ Robert Klewicki $^{2} \cdot$ Agnieszka Milczarek $^{2} \cdot$ Lidia Lipińska $^{1,3}$. \\ Krzysztof Kołodziejczyk ${ }^{2}$
}

Received: 11 January 2020 / Revised: 30 March 2020 / Accepted: 4 April 2020 / Published online: 11 April 2020

(c) The Author(s) 2020

\begin{abstract}
Alternaria spp. fungi, characterized by a high tolerance to unfavorable environmental conditions, are one of the threats for foods of plant origin. The increasing incidence of diseases caused by a demanding lifestyle, and a higher social awareness of the role of a diet in maintaining health and good condition, results in the dynamically growing demand for natural protective measures that would be safe for consumers. Ellagitannins, i.e. a group of bio-active polyphenols, may constitute an alternative for chemical preservatives. Studies demonstrated that the raspberry (Rubus idaeus L.) ellagitannin formula limited the growth of Alternaria alternata 0409 . The minimal inhibitory concentration (MIC) was determined $(0.156 \mathrm{mg} / \mathrm{ml})$, along with the minimal fungicidal concentration (MFC) $(0.312 \mathrm{mg} / \mathrm{ml})$. The fungistatic (FA) activity and the ratio of linear growth (T) were also determined for the ellagitannin formula. A strong antimycotic activity of ellagitannins was demonstrated at the formula level of $0.1 \mathrm{mg} / \mathrm{ml}$. Unfortunately, the activity was not maintained over time and after 9 days it was only $16.0 \%$. For the ellagitannin formula, concentrations of $0.312 \mathrm{mg} / \mathrm{ml}$ (MFC) and $0.5 \mathrm{mg} / \mathrm{ml}$ (below the MFC value), a complete arrest of growth of Alternaria alternata 0409 was observed, and it was maintained for 9 days. The antimycotic activity of the ellagitannin formula was also confirmed in food environment, with cottage cheese and cherry tomatoes used as the matrix. Results confirmed that ellagitannins from raspberry (Rubus idaeus L.) could be successfully used as a natural food preservative.
\end{abstract}

Keywords Ellagitannins $\cdot$ Antimycotic activity $\cdot$ Food safety $\cdot$ Fungi $\cdot$ Raspberry

\section{Introduction}

Strains of fungi belonging to the Alternaria genus are common in the plant environment. Those fungi naturally occur in soil, but also function as plant saprophytes and pathogens. Alternaria strains produce over 70 secondary metabolites, including numerous mycotoxins. Four mycotoxins produced by Alternaria spp. were classified as the most hazardous for humans and animals: alternariol ( $\mathrm{AOH})$, alternariol monomethyl ether (AME), tenuazonic acid (TeA) and tentoxin

Sylwia Ścieszka

sylwia.scieszka@edu.p.lodz.pl

1 Institute of Fermentation Technology and Microbiology, Lodz University of Technology, Wólczańska 171/173, 90-924 Lodz, Poland

2 Institute of Food Technology and Analysis, Lodz University of Technology, Stefanowskiego 4/10, 90-924 Lodz, Poland

3 Institute of Genetics and Biotechnology, University of Warsaw, Pawińskiego 5a, 02-106 Warsaw, Poland
(TEN) [1]. Alternaria strains (A. alternata, A. tenuissima, A. arborescens, A. radicina, A. brassicae, A. brassicicola, A. infectoria) pollute food of plant origin, including: tomatoes, apples, grapes, oranges, lemons, tangerines, melons, cucumbers, cauliflowers, peppers, cereal grains, oil plants grains [2]. Despite the fact that the optimum temperature for the growth of Alternaria spp. ranges between 22 and $30{ }^{\circ} \mathrm{C}$, those fungi are able to develop at minimal temperatures $\left(2.5-6.5^{\circ} \mathrm{C}\right)$, and even in temperatures below the minimum-from 0 to $-5{ }^{\circ} \mathrm{C}[3,4]$. Additionally, they tolerate reduced water activity values very well. Spores of Alternaria spp. germinate with a water activity ranging between 0.84 and 0.995 in the environment, and vegetative forms are able to grow even below the water activity of 0.85 . A high tolerance to unfavorable $\mathrm{pH}$ of the environment should be also considered. Growth of Alternaria spp. is observed in the $\mathrm{pH}$ range of 2.5-10.0 [2]. With that high tolerance to unfavorable conditions of the growth environment, and considering that food of plant origin may be such an environment, it seems necessary to search for effective and consumer-safe 
preservatives. Natural plant extracts and essential oils which contain phytochemicals offer an alternative for chemical preservatives [5].

Raspberry (Rubus idaeus L.) belongs to the Rosaceae family. The plant grows wild in Europe and Northern Asia, and is cultivated by farmers in many regions of the world [6]. Raspberry fruits are valued not only for their taste, but also for nutritional and medicinal properties. In many countries they are used for wound healing, pain soothing, as a remedy for colic, as a diuretic, and also to treat other conditions, including diarrhea and kidney diseases [7]. Raspberry fruit contains macro-, microelements and vitamins. They are also rich in phenolic compounds, such as flavonoids, phenolic acids and tannins, including ellagitannins, i.e. the esters of hexahydroxydiphenic acid (HHDP) and a monosaccharide, mostly $\beta$-D-glucose. They may have a form of mono-, oligo-, or polymers, containing one, several to over ten glucose molecules. Ellagitannin monomers contain one glucose molecule with attached residues of HHDP, and sometimes also of gallic acid. Oligo- and polymers of ellagitannins are formed as a result of polymerization of monomers $[8,9]$. The main ellagitannins found in raspberries are trimeric lambertianin $\mathrm{C}$ and dimeric sanguiin H-6 (Fig. 1), with the content in fruit up to $300-700 \mathrm{mg} / \mathrm{g}$ for each of the compounds [10].

A growing interest in the biological activity of molecules present in non-processed food has been observed over the recent years. Polyphenols - the group to which ellagitannins are classified-constitute a significant part of those compounds. Research on the biological activity of ellagitannins demonstrated that the antibacterial effect was the principal type of ellagitannin interaction. Studies completed so far demonstrated that ellagitannin-rich berries limit the development of Campylobacter jejuni, Helicobacter pylori, Bacillus cereus and Clostridium perfringens, and also inhibit the development of Staphylococcus aureus and Staphylococcus aureus (MRSA) [11, 12]. Moreover, they demonstrate antimicrobial activity against Candida parapsilosis yeasts [13] and Alternaria alternata, Fusarium oxysporum, Colletotrichum gloeosporioides and Rhizoctonia solani fungi [14].

The purpose of the study was to determine the in vitro and in situ antimycotic activity of the ellagitannin formula from raspberry (Rubus idaeus L.) against Alternaria alternata 0409.

We hypothesize that ellagitannin formula from raspberry (Rubus idaeus L.) has antimycotic activity against Alternaria alternata 0409. Therefore it may be successfully used as a food preservative.

\section{Materials and methods}

\section{Plant material}

The formula containing $765 \mathrm{mg} / \mathrm{g}$ of ellagitannins produced from raspberry fruit (Rubus idaeus L.) according to

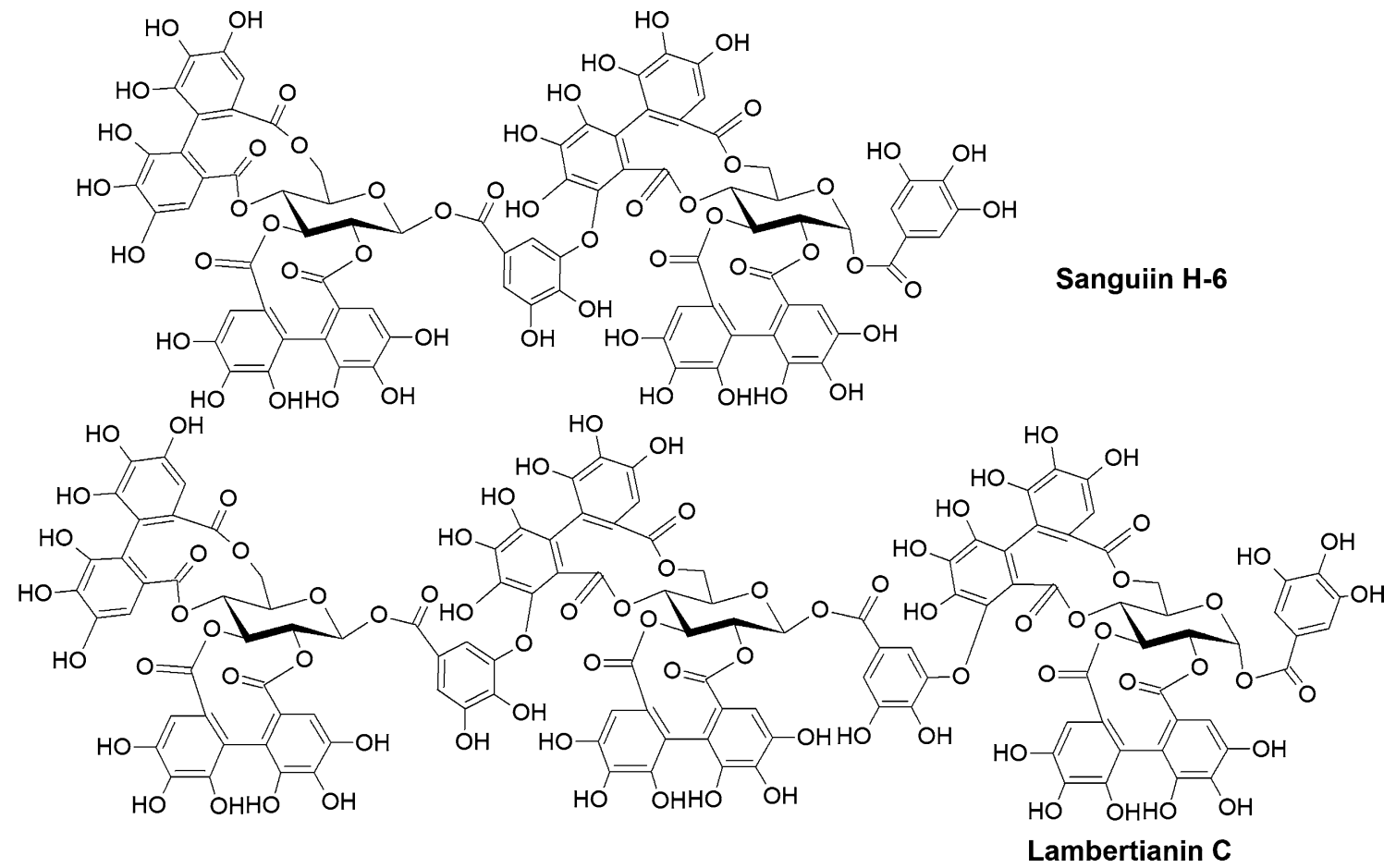

Fig. 1 Structures of major Rubus idaeus L. ellagitannins: sanguiin H-6 and lambertianin C 
the procedure described previously [15] was used as the experiment material. The formula was made of fruit pomace after production of juice, in laboratory conditions, from the 'Polka' variety raspberries purchased from the Cajdex company (Łódź, Poland). In short, the extraction of ellagitannins was carried out at room temperature for $8 \mathrm{~h}$, using a $60 \%$ acetone solution, with the pomace to extraction solvent ratio of $1: 5(\mathrm{~m} / \mathrm{v})$. Acetone was removed from the raw extract using a rotating laboratory evaporator. Next, the extract was purified on the $90 \mathrm{~cm} \times 1.6 \mathrm{~cm}$ chromatographic column packed with Amberlite XAD 1600 N (DOW, Midland, MI, USA). Ellagitannins were eluted from the column using a water and ethanol solution, the concentration of which increased from 10 to $60 \%$. Majority of ellagitannins present in the raw extract was desorbed from the column when the $40 \%$ ethanol solution was applied to the column. Furthermore, ethanol was removed from the purified extract with the use of a rotating laboratory evaporator. The resulting extract was freeze-dried $\left(-36^{\circ} \mathrm{C}, 24 \mathrm{~h}\right.$; Christ, Alpha 1-2 LDplus, Osterode am Harz, Germany). The final formula was a red powder with a high ellagitannin content.

\section{Determination of polyphenolic compounds in the studied formula}

Content of individual ellagitannins, total flavanol and total anthocyanin content were determined in the formula. The qualitative and quantitative analysis of ellagitannins and other polyphenols was completed according to the previously described procedure, using the same research equipment [15]. Briefly, the UHPLC Dionex Ultimate 3000 chromatograph (Germering, Germany) with the mass detector $\mathrm{Q}$ Exactive Orbitrap (Thermo Fisher Scientific, Bremen, Germany) was used for the qualitative analysis of ellagitannins. Separation was carried out by the use of Luna C18 $250 \times 4.6$ i.d., $5 \mu \mathrm{m}$ column (Phenomenex, Torrance, CA, USA), and the following solvents were used: solvent $\mathrm{A}, 1 \%(\mathrm{v} / \mathrm{v})$ formic acid in water and solvent $\mathrm{B}$, an 80:20 (v/v) acetonitrile:water solution. The column temperature was set at $35^{\circ} \mathrm{C}$, the flow rate was $1 \mathrm{ml} / \mathrm{min}$, and the injection volume was $20 \mu \mathrm{l}$. Chromatographic data were collected using Xcalibur software (Thermo Fisher Scientific, Waltham, MA, USA). The MS source parameters were as follows: negative mode, vaporizer temperature $500{ }^{\circ} \mathrm{C}$, ion spray voltage $4 \mathrm{kV}$, capillary temperature $400{ }^{\circ} \mathrm{C}$, with sheath gas and auxiliary gas flow rates being 75 and 20 units, respectively. To generate $\mathrm{MS}^{2}$ data the normalized collision energy (NCE) was set to $20 \mathrm{eV}$ in HDC collision cell. The identification of researched ellagitannins was the same as described in our previous publication [15].

Smartline HPLC chromatograph from Knauer (Berlin, Germany) was used for the quantitative analysis. Ellagitannins were separated on Gemini C18 110A column $250 \times 4.6 \mathrm{~mm}$ i.d., $5 \mu \mathrm{m}$ (Phenomenex) by gradient elution with $0.05 \%$ (v/v) phosphoric acid in water (solvent $\mathrm{A}$ ), and 83:17 (v/v) acetonitrile:water with $0.05 \%$ phosphoric acid (solvent B). The column temperature was set to $35^{\circ} \mathrm{C}$, the flow rate was $1.25 \mathrm{ml} / \mathrm{min}$, and the gradient program the same as described in our previous work [15]. Ellagitannins were detected at $250 \mathrm{~nm}$, and standard curves for lambertianin $\mathrm{C}$ and sanguiin $\mathrm{H}-6$ were used for quantification.

Minor polyphenols (anthocyanins and flavanols) of studied formula was quantified using the same protocol given in previous publication [15].

\section{Microorganisms}

The study involved Alternaria alternata 0409, a strain of filamentous fungi deposited with the Collection of Industrial Microorganisms of the Institute of Fermentation Technology and Microbiology ŁOCK 105, Lodz University of Technology (Poland). The strain was stored on YEA slants (Yeast Extract Agar, Sigma-Aldrich, Saint Louis, MO, USA) at $4{ }^{\circ} \mathrm{C}$ and activated either on Sabouraud dextrose broth or on agar (Merck KGaA, Darmstadt, Germany), as need be.

\section{Inhibition of Alternaria alternata growth by ellagitannins}

The antifungal properties, minimal inhibitory concentration (MIC), and minimal fungicidal concentration (MFC) of the ellagitannin preparation (REP), was determined by the broth dilution method in test tubes. Ellagitannin solutions were prepared and diluted in DMSO $(50 \mathrm{mg} / \mathrm{ml})$ (Merck). Subsequently, $100 \mu \mathrm{l}$ of diluted ellagitannin solutions were added to $4.9 \mathrm{ml}$ of Sabouraud dextrose broth (Merck) containing a suspension of spores at a concentration of $10^{5}$ spores $/ \mathrm{ml}$, so that the final ellagitannin concentration ranged from $0.05 \mathrm{mg} / \mathrm{ml}$ to $30 \mathrm{mg} / \mathrm{ml}$. The samples were incubated at $30^{\circ} \mathrm{C}$ for $96 \mathrm{~h}$. The minimum inhibitory concentration was defined as the lowest concentration of the compound that inhibited visible growth of the fungus. Subsequently, $1 \mathrm{ml}$ was collected from the samples with no visible growth and plated on Sabouraud dextrose agar. The samples were incubated at $30{ }^{\circ} \mathrm{C}$ for $72 \mathrm{~h}$. The minimum fungicidal concentration was defined as the lowest concentration of the compound leading to no fungal growth [13].

\section{Linear growth rate of filamentous Alternaria alternata in the presence of ellagitannins}

Ellagitannin-induced inhibition of the linear growth rate of Alternaria alternata $\mathrm{ŁOCK} 0409$ was studied by means of the poisoned medium method [16]. Sabouraud dextrose agar (Merck) was supplemented with $0.025 \mathrm{mg} / \mathrm{ml}, 0.05 \mathrm{mg} / \mathrm{ml}$, $0.1 \mathrm{mg} / \mathrm{ml}, 1.0 \mathrm{mg} / \mathrm{ml}$, of REP (the amounts specified refer to ellagitannin content). The control was a culture without 
REP. Tests were done in triplicate. The linear growth rate of Alternaria alternata ( $T$ ) was calculated based on fungal growth measurements performed every $24 \mathrm{~h}$ according to the formula:

$T=(A / D)+\left(b_{1} / d_{1}\right)+\cdots+\left(b_{n} / d_{n}\right)(\mathrm{mm} /$ day $)$,

where $T$ is the linear growth rate, $A$ is the mean fungal colony diameter in $\mathrm{mm}, D$ is the duration of the experiment, $b_{1} \ldots b_{n}$ is the colony diameter growth in $\mathrm{mm}, d_{1} \ldots d_{n}$ is the number of days since the last measurement. The fungistatic activity of ellagitannins (FA) against filamentous fungi was determined based on fungal growth inhibition calculated according to the formula:

$\mathrm{FA}=((K-A) / K) \times 100 \%$,

where FA is the fungistatic activity in $\%, K$ is the mean fungal colony diameter on the control plate, $A$ is the mean fungal colony diameter on the plate containing ellagitannins. The experimental data are expressed as mean values. Oneway analysis of variance (ANOVA, $p \leq 0.05$ ) was applied to find differences between the experimental samples and the control samples.

\section{Loss of $260 \mathrm{~nm}$-absorbing material (nucleic acids)}

Alternaria alternata was inoculated into Sabouraud dextrose broth (Merck) medium and incubated at $30^{\circ} \mathrm{C}$ for $72 \mathrm{~h}$. The inoculum was prepared by suspending A. alternata conidia in PBS buffer $\mathrm{pH}$ 7.0. The inoculum density was set at $5 \times 10^{4}$ conidia/ml. Counting method in Thoma chamber was used for inoculum standardization. Then added ellagitannin preparation $(\mathrm{REP})$ at $1 \times, 2 \times$ and $10 \times \mathrm{MIC}$ which corresponded $0.156,0.312$ and $1.560 \mathrm{mg} / \mathrm{ml}$. Incubation was provide at $30^{\circ} \mathrm{C}$ for $48 \mathrm{~h}$. After $0,8,18,24$ and $48 \mathrm{~h}$ of incubations suspension was centrifuged ( $5 \mathrm{~min}$ at $4000 \mathrm{rpm}$ ) and the absorbance of the supernatants was measured at $260 \mathrm{~nm}$ (Spectrophotometer V-VIS T-60 PG Instruments, UK). The control sample was the sample prepared in the same way as the tested samples without the addition of REP. The study was carried out in three independent repetitions. The experimental data are expressed as mean values. One-way analysis of variance (ANOVA, $p \leq 0.05$ ) test was applied to find differences between the study samples toward control sample.

\section{In situ effect of the raspberry ellagitannin preparation}

The in situ antagonistic activity of REP against Alternaria alternata was determined in cottage cheese ("JOGO" Łódzka Spółdzielnia Mleczarska (Dairy Cooperative of Lodz), Łódź, Poland) and cherry tomatoes (Solanum lycopersicum var. cerasiforme).
A $10 \mathrm{~g}$ sample of cottage cheese was inoculated with suspension of Alternaria alternata spores, with a density of $10^{5}$ spores per $1 \mathrm{ml}$. The amount of suspension added was $1 \%$ (v/g). Cheese was carefully mixed and divided into two parts. Next, the ellagitannin formula at the concentration of $0.312 \mathrm{mg} / \mathrm{g}$ of cheese was added to one part of cheese inoculated with Alternaria alternata spores. Cheese samples were stored at $30{ }^{\circ} \mathrm{C}$. Macroscopic observations of cheese samples were carried out for 10 days.

Cherry tomatoes (Solanum lycopersicum var. cerasiforme) were purchased in the "Bio" products shop. The producer declared ecological conditions of culture. Tomatoes were produced in Spain, AGRO BIO TEST PL-EKO-07 certification, batch no.: 08/01/2019. Before testing, tomatoes were washed under pure and sterile water and wiped dry with a piece of sterile tissue. Next, single tomatoes were placed in individual, sterile containers. A pure tomato was the negative control, while a tomato inoculated by injection and introduction of $10 \mu \mathrm{l}$ of Alternaria alternata spore suspension, density of $10^{5}$ spores per $1 \mathrm{ml}$, was the positive control. The test sample was a tomato injected with the $0.312 \mathrm{mg} / \mathrm{g}$ ellagitannin formula, and further inoculated with Alternaria alternata in the same manner as the positive sample. Tomatoes were stored in optimal conditions for the development of fungi $\left(30{ }^{\circ} \mathrm{C}\right)$ for 7 days. Afterwards, macroscopic assessment of the tomato surface was made after seven days.

\section{Microscopic analysis}

Photomicrographs of Alternaria alternata mycelium were acquired with a Nikon Eclipse Ci H600L (Nikon, Tokyo, Japan) microscope (total magnification $400 \times$ ) operated with NIS-Elements Advanced Research v. 3.0 software (Nikon). At least 20 fields of view of 1 preparation were analyzed. The study was carried out in 3 independent repetitions.

\section{Results \\ Polyphenolic composition of the ellagitannin formula}

The qualitative characteristics of the obtained ellagitannin formula are presented in Table 1. Total content of ellagitannins was $765 \mathrm{mg} / \mathrm{g}$, where, two ellagitannins, namely lambertianin $\mathrm{C}$ and sanguiin H-6, were predominant (Fig. 2), and their content was $411 \mathrm{mg} / \mathrm{g}$ and $280 \mathrm{mg} / \mathrm{g}$, respectively. The formula had also the flavanol content at the level of $69 \mathrm{mg} / \mathrm{g}$ and a minor content of anthocyanins $(0.7 \mathrm{mg} / \mathrm{g})$, responsible for red color of the formula. Total polyphenol content in the formula was $835 \mathrm{mg} / \mathrm{g}$. The resulting formula 
Table 1 LC-MS identification of ellagitannins and phenolics composition of raspberry ellagitannin formula

\begin{tabular}{lc}
\hline Compound & $\begin{array}{c}\text { Quantity }(\mathrm{mg} / \mathrm{g}) \\
\text { mean } \pm \operatorname{SD}(n=3)\end{array}$ \\
\hline Sanguiin H-10 isomer & $9 \pm 1$ \\
Lambertianin C without ellagic moiety & $14 \pm 1$ \\
Sanguiin H-10 isomer & $7 \pm 1$ \\
Lambertianin C isomer & $44 \pm 2$ \\
Lambertianin C & $411 \pm 27$ \\
Sanguiin H-6 & $280 \pm 21$ \\
Total flavanols & $69 \pm 2$ \\
Total anthocyanins & $0.7 \pm 0.0$ \\
\hline
\end{tabular}

$n$ number of repetitions, $S D$ standard deviation

had a similar polyphenolic composition as described in our previous publication [15].

\section{Inhibition of Alternaria alternata growth by ellagitannins}

The obtained ellagitannin formula inhibited the growth of Alternaria alternata 0409. Determined MIC and MFC values were $0.156 \mathrm{mg} / \mathrm{ml}$ and $0.312 \mathrm{mg} / \mathrm{ml}$, respectively (Table 2). Those concentrations were higher from the applied Nystatin concentration causing inhibition of the growth of the analyzed fungus (positive control).

\section{Linear growth rate of filamentous Alternaria alternata in the presence of ellagitannins}

The fungistatic activity (FA) and the rate of linear growth $(T)$ for the ellagitannin formula were determined over the range of concentrations: $0.025 \mathrm{mg} / \mathrm{ml}, 0.05 \mathrm{mg} / \mathrm{ml}, 0.1 \mathrm{mg} /$ $\mathrm{ml}, 0.5 \mathrm{mg} / \mathrm{ml}$ and $1.0 \mathrm{mg} / \mathrm{ml}$. No inhibitory activity against the growth of Alternaria alternata 0409 was observed for the lowest concentration of the ellagitannin formula of
Table 2 Minimal inhibitory concentration (MICs), and minimal fungicidal concentration (MFC) of ellagitannin extract from raspberries against Alternaria alternata 0409

\begin{tabular}{llll}
\hline Species & MIC $(\mathrm{mg} / \mathrm{ml})$ & MFC $(\mathrm{mg} / \mathrm{ml})$ & Nystatin $^{\mathrm{a}}(\mathrm{mg} / \mathrm{ml})$ \\
\hline $\begin{array}{l}\text { Alternaria alter- } \\
\text { nata } 0409\end{array}$ & 0.156 & 0.312 & 0.063 \\
\hline
\end{tabular}

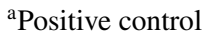

$0.025 \mathrm{mg} / \mathrm{ml}$ for 9 days. The FA index fell within in the range of values over $19.9 \%$ on the day 3 of the action of the ellagitannin formula, and under $16.1 \%$ on the day 9 . The rate of linear growth for the concentration of $0.025 \mathrm{mg} / \mathrm{ml}$ of the ellagitannin formula was $35.0 \mathrm{~mm} /$ day for the test sample, and $39.1 \mathrm{~mm} /$ day for the control (no ellagitannins). Statistical analysis of the above experimental data demonstrated no statistically significant differences (Table 3 ). Statistically significant inhibition of the growth of Alternaria alternata 0409 by the analyzed ellagitannin formula was observed at the level of $0.05 \mathrm{mg} / \mathrm{ml}\left(p=2.85 \times 10^{-8}\right)$. Depending on the duration of the experiment, FA for that concentration of ellagitannin formula ranged between $40 \%$ after three days of incubation, and $42 \%$ after 9 days of interaction between fungi and ellagitannins. At the ellagitannin formula concentration of $0.05 \mathrm{mg} / \mathrm{ml}$, a reduction in the rate of growth by $30 \%$ compared to the rate of growth of the control sample was observed. For the ellagitannin formula concentration of $0.1 \mathrm{mg} / \mathrm{ml}$ (slightly below the MIC level of $0.156 \mathrm{mg} /$ $\mathrm{ml}$ ), a strong fungicidal activity of the analyzed formula was observed. FA for the day 3 of the formula action was $98 \%$. Unfortunately, the activity was not maintained over time, and after 5 days of incubation was $36.5 \%$, and after 9 days only $16.0 \%$. The value of the index of linear growth $(T)$ was $12.0 \mathrm{~mm} /$ day, and was statistically different from the index of growth of the control sample $\left(37.1 \mathrm{~mm} /\right.$ day; $\left.p=8 \times 10^{-6}\right)$ (Table 3). For the ellagitannin formula concentration of $0.312 \mathrm{mg} / \mathrm{ml}$ (MFC) and $0.5 \mathrm{mg} / \mathrm{ml}$ (below the MFC value) a complete arrest of the growth of Alternaria alternata

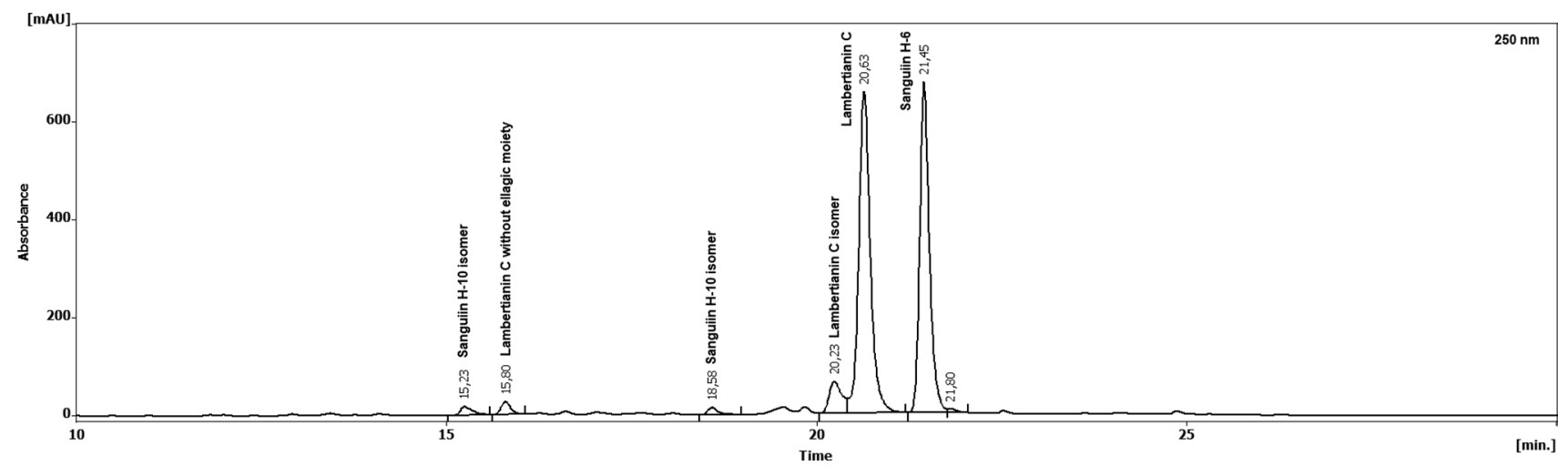

Fig. 2 HPLC chromatogram of ellagitannin formula obtained from raspberries (250 nm) 
Table 3 Fungistatic activity (FA) of the ellagitannin extract and the index of linear growth (T) for Alternaria alternata 0409

\begin{tabular}{|c|c|c|c|c|c|c|}
\hline \multirow{3}{*}{$\begin{array}{l}\text { Ellagitannins } \\
(\mathrm{mg} / \mathrm{ml})\end{array}$} & \multicolumn{4}{|c|}{ FA $(\%)$} & \multirow{3}{*}{$\begin{array}{l}\text { Growth rate } \\
\text { index } \\
T_{\text {Ellagitannins }}(\mathrm{mm} / \\
\text { day) }\end{array}$} & \multirow{3}{*}{$\begin{array}{l}\text { Growth } \\
\text { rate index } \\
T_{\text {Control }} \\
\text { (mm/day) }\end{array}$} \\
\hline & \multicolumn{4}{|c|}{ Time (days) } & & \\
\hline & 3 & 5 & 7 & 9 & & \\
\hline 0.025 & 19.9 & 18.1 & 17.3 & 16.1 & $35.0 *$ & $39.1 *$ \\
\hline 0.05 & 40.0 & 45.9 & 46.0 & 42.0 & $28.1 * *$ & 40.2 \\
\hline 0.1 & 98.0 & 36.5 & 29.7 & 16.0 & $12.0 * * *$ & 37.1 \\
\hline 0.312 & 100.0 & 100.0 & 100.0 & 100.0 & - & 38.8 \\
\hline 0.5 & 100.0 & 100.0 & 100.0 & 100.0 & - & 38.0 \\
\hline
\end{tabular}

*Statistically significant difference $T_{\text {Ellagitannins }}$ versus $T_{\text {Control }}(p=0.0678)$

**Statistically significant difference $T_{\text {Ellagitannins }}$ versus $T_{\text {Control }}\left(p=2.85 \times 10^{-8}\right)$

***Statistically significant difference $T_{\text {Ellagitannins }}$ versus $T_{\text {Control }}\left(p=8 \times 10^{-6}\right)$
0409 was observed, which was maintained for 9 days of the experiment.

\section{Loss of $260 \mathrm{~nm}$-absorbing material (nucleic acids)}

The leaked intracellular substance from the cells of the mycelium of A. alternata was determined by measuring absorbance at $260 \mathrm{~nm}\left(A_{260}\right)$. The absorbance measurement at this wavelength is used to determine the concentration of nucleic acids. REP at concentrations of $0.156 \mathrm{mg} / \mathrm{ml}$ (MIC), $0.312 \mathrm{mg} / \mathrm{ml}(2 \times \mathrm{MIC}=\mathrm{MFC})$ and $1.560 \mathrm{mg} / \mathrm{ml}(10 \times \mathrm{MIC})$ was used as a factor causing loosening of the cell's external structures. In the test using REP concentration equal to MIC value, there was no increase in absorbance during the experiment (Table 4). The $A_{260}$ value for these trials varied between 1.12 and 1.48 and was comparable to the control. After using REP at a concentration of $2 \times$ MIC (MFC), an increase of the $A_{260}$ value was observed (by 1.59 unit) after an $8 \mathrm{~h}$ incubation; a further increase was observed at subsequent measuring points. After $48 \mathrm{~h}$ of REP interaction on $A$. alternata mycelium cells, an $A_{260}$ increase to $4.80 \pm 0.255$ (increase by 3.61 units) was found. A similar phenomenon was observed when REP at a concentration of $10 \times$ MIC was added to A. alternata. After $8 \mathrm{~h}$, the $A_{260}$ value was $3.56 \pm 0.491$, and after $48 \mathrm{~h}-5.07 \pm 0.061$. The differences between the results obtained for the control sample (without
REP) and the results for REP $2 \times$ MIC and $10 \times$ MIC are statistically significant.

\section{In situ effect of the raspberry ellagitannin formula}

The fungicidal activity of the ellagitannin formula was tested in the food environment. Cottage cheese was used as a matrix. After 10 days of incubation the sample inoculated with Alternaria alternata 0409 (no addition of ellagitannins) changed color into yellow (Fig. 3a). Moreover, cheese had a distinct, irritating odor. No gross changes nor altered fragrance were observed in the cottage cheese sample with the ellagitannin formula (Fig. 3b). Cheese storage conditions such as $30^{\circ} \mathrm{C}$ and the time of 10 days are not recommended by the cheese manufacturer. However, using those "extreme" storage conditions of the product, a high preservative efficacy of ellagitannins against Alternaria alternata 0409 was demonstrated.

For the tests of Alternaria alternata 0409 growth inhibition on a plant matrix, we used cherry tomatoes (Solanum lycopersicum var. cerasiforme). After 7 days of incubation, deformation of a tomato was observed in the negative control, and no macroscopic features of microbial pollution (Fig. 4a). In the positive control, an intensive growth $(20.0 \pm 1.00 \mathrm{~mm})$ of Alternaria alternata was observed on the tomato surface, along with deformation of a single
Table 4 Leakage of substances absorbing at $260 \mathrm{~nm}$ from A. alternata incubated with ellagitannin preparation (REP)

\begin{tabular}{|c|c|c|c|c|c|}
\hline \multirow{3}{*}{$\begin{array}{l}\text { Ellagitannins } \\
(\mathrm{mg} / \mathrm{ml})\end{array}$} & \multicolumn{5}{|l|}{$A_{260}$} \\
\hline & \multicolumn{5}{|l|}{ Time (h) } \\
\hline & 0 & 8 & 18 & 24 & 48 \\
\hline 0.000 & $1.02 \pm 0.072$ & $1.07 \pm 0.110^{\mathrm{a}}$ & $1.14 \pm 0.059^{\mathrm{a}}$ & $1.27 \pm 0.262^{\mathrm{a}}$ & $1.40 \pm 0.092^{\mathrm{a}}$ \\
\hline 0.156 & $1.21 \pm 0.065$ & $1.12 \pm 0.117^{\mathrm{a}}$ & $1.28 \pm 0.183^{\mathrm{a}}$ & $1.41 \pm 0.454^{\mathrm{a}}$ & $1.48 \pm 0.352^{\mathrm{a}}$ \\
\hline 0.312 & $1.19 \pm 0.011$ & $2.78 \pm 0.211^{\mathrm{b}}$ & $3.58 \pm 0.264^{b}$ & $4.03 \pm 0.058^{b}$ & $4.80 \pm 0.255^{\mathrm{b}}$ \\
\hline 1.560 & $1.04 \pm 0.038$ & $3.56 \pm 0.491^{\mathrm{c}}$ & $4.48 \pm 0.300^{c}$ & $4.71 \pm 0.078^{c}$ & $5.07 \pm 0.061^{b}$ \\
\hline
\end{tabular}

${ }^{\mathrm{a}, \mathrm{b}, \mathrm{c}}$ Statistically significant differences between the control sample and experimental samples with ellagitannins $(p \leq 0.05)$ 
fruit (Fig. 4b). When the ellagitannin formula at the concentration of $0.312 \mathrm{mg} / \mathrm{g}$ was applied before the inoculation with spores, a minor and local development of fungus $(3.0 \pm 0.50 \mathrm{~mm})$ was observed, and the tomato was firm and not deformed (Fig. 4c).

As previously, a high efficacy of the raspberry ellagitannin formula (Rubus idaeus L.) was observed in the inhibition of growth of Alternaria alternata 0409 on the plant matrix.

\section{Microscopic analysis}

Fresh samples were analyzed under a light microscope. Septate hyphae and abundant yellow-rusty conidia were observed in the control sample (Fig. 5a). In the sample in which the $0.156 \mathrm{mg} / \mathrm{ml}$ ellagitannin formula (MIC level) was added to the growth medium only hyphae were noted, with no conidia in any of the analyzed fields of the analyzed fresh sample (Fig. 5b). Therefore, the inhibition of spore production is one of the mechanisms of antagonistic action of the analyzed raspberry formula against Alternaria alternata 0409.

\section{Discussion}

A high efficacy of the raspberry ellagitannin formula (Rubus idaeus L.) was observed in the inhibition of growth of Alternaria alternata 0409 . The applied formula contains multiple
Fig. 3 Samples of cottage cheese contaminated with Alternaria alternata 0409 spores after 10 days of storage at $30^{\circ} \mathrm{C}$ a without ellagitannins, $\mathbf{b}$ with the ellagitannin formula at the concentration of $0.312 \mathrm{mg} / \mathrm{g}$ of cheese
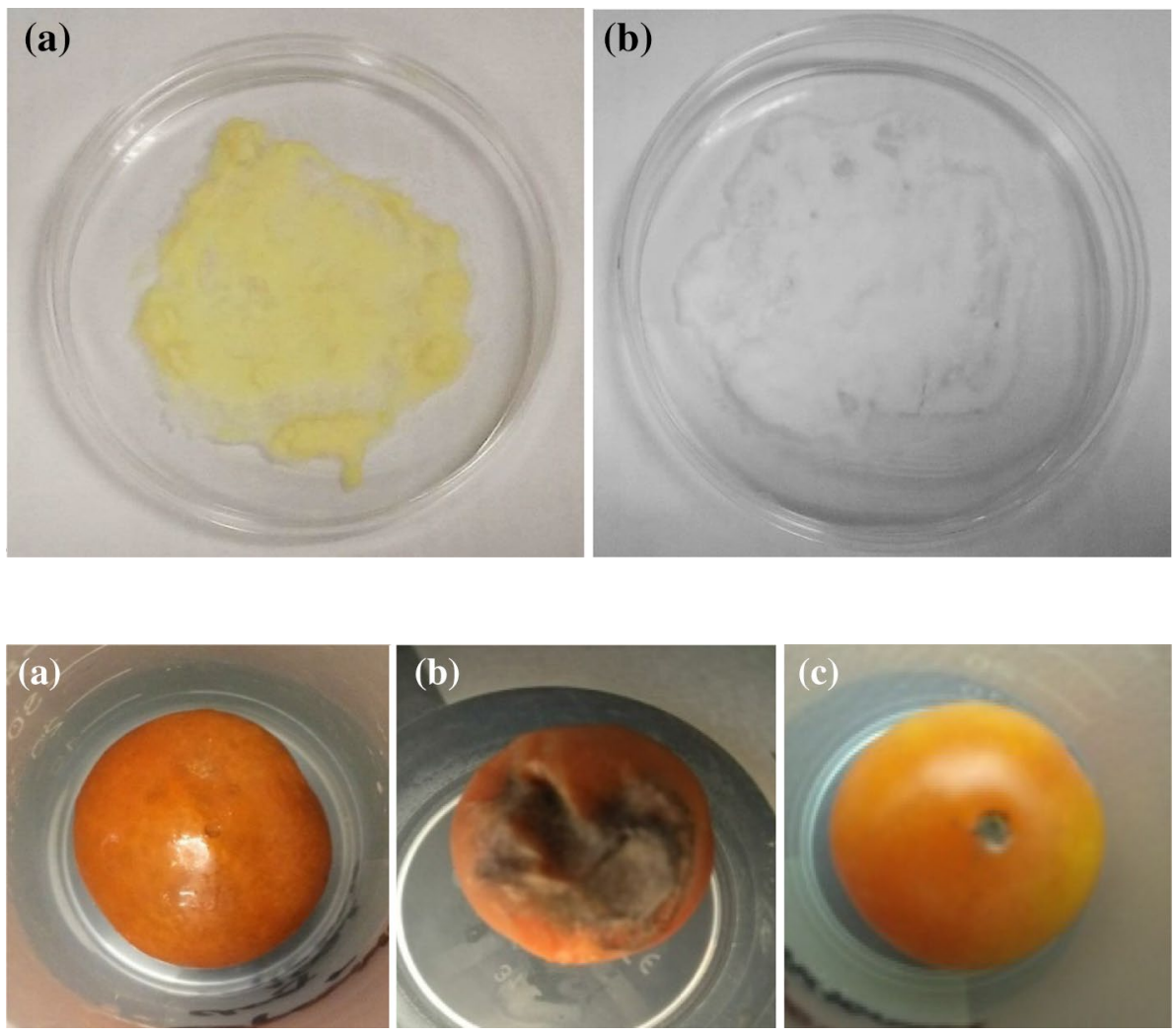
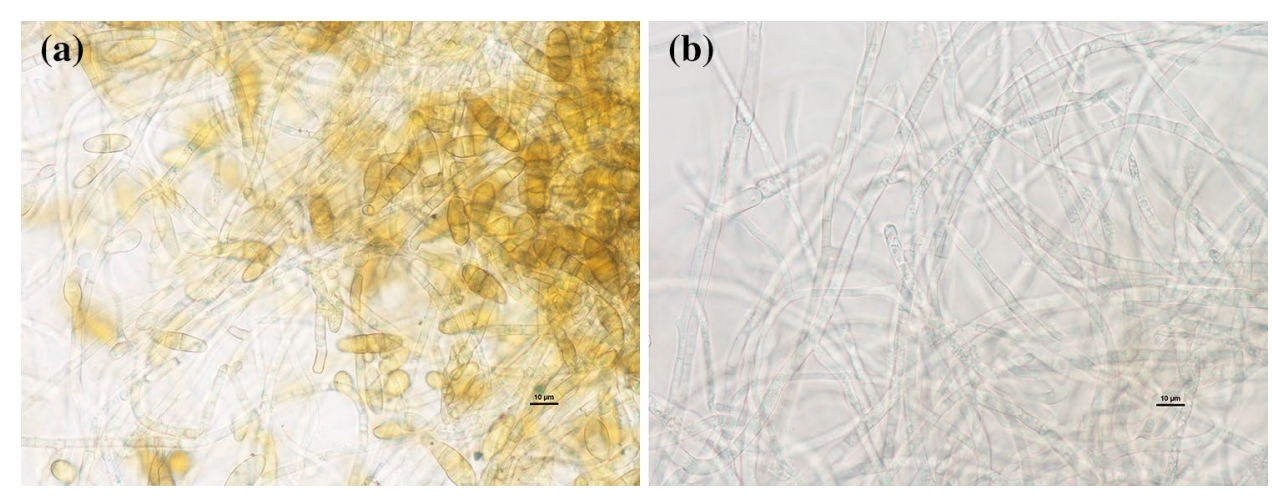

Fig. 5 Photographs of Alternaria alternata 0409 hyphae under the light microscope, a control, $\mathbf{b}$ in the presence of the $0.156 \mathrm{mg} / \mathrm{ml}$ ellagitannin formula
Fig. 4 Cherry tomatoes (Solanum lycopersicum var. cerasiforme) inoculated with after 7 days of incubation at $30^{\circ} \mathrm{C}$; a negative control $(0.0 \pm 0.00 \mathrm{~mm}), \mathbf{b}$ positive control $(20.0 \pm 1.00 \mathrm{~mm})$ $0.312 \mathrm{mg} / \mathrm{g}$ ellagitannin formula $(3.0 \pm 0.50 \mathrm{~mm})$ 
compounds, with the following dominating bio-active ones: Lambertianin C, Sanguiin H-6, H-10 with the total ellagitannin content of $961 \mathrm{mg} / \mathrm{g}$. The complete formula was used in experiments, with no fractionation into dominating compounds. Previous studies did not demonstrate a statistically significant difference between the antagonistic activity of the whole formula and its leading fractions (Lambertianin C, Sanguiin H-6) [15]. The MIC value for the ellagitannin formula against Alternaria alternata 0409 is $0.156 \mathrm{mg} / \mathrm{ml}$, and the MFC value against this microorganism is $0.312 \mathrm{mg} /$ $\mathrm{ml}$. Zhang et al. [17] studied the inhibition of growth of Alternaria alternata on strawberries by benzo- $(1,2,3)$ thiadiazole-7-carbothioic acid $S$-methyl ester (BTH) at the concentration of $0.1 \mathrm{mg} / \mathrm{ml}$. Unfortunately, with no success. Only the combination of the chemical factor BTH and Cryptococcus laurentii bacteria effectively inhibited the growth of Alternaria alternata on the PDA medium (in vitro conditions). Another team of researchers studied a mixture of chitosan and methyl jasmonate (MeJA) as a protective measure for cherry tomato fruit against Alternaria alternata. Those authors demonstrated that MeJA at the concentration of $500 \mu \mathrm{l} / \mathrm{l}$ inhibited the growth of Alternaria alternata by $50 \%$. On the other hand, a combination of $0.1 \%$ chitosan and $500 \mu \mathrm{l} / \mathrm{l} \mathrm{MeJA}$ caused the inhibition of growth of the fungus by $56.9 \%$. Moreover, the applied combination of chitosan and MeJA inhibited sporulation of Alternaria alternata by 99.67\% [18]. In this study, we observed a similar mechanism of action of the raspberry ellagitannin formula (Rubus idaeus L.), consisting in the inhibition of sporulation and growth of mycelium. Dutreix et al. [19] studied the fungicidal activity of raspberry extracts against Candida spp., and found it effective in the limitation of adhesion properties of Candida spp. The following are identified as principal bioactive compounds of the raspberry extract: sanguiins H5, H6, H10 [20], gallic acid derivatives, including: monogalloyl glucose and hexahydroxydiphenic (HHDP)-glucose [19, 21, 22]. According to literature [20] Sanguiin H5, H6 and H10 inhibit the activity of microbial $\alpha$-amylase.

Among the known antibacterial mechanisms of tannins researchers list the inhibition of catalase activity in bacterial cells (Klebsiella pneumoniae, Staphylococcus aureus, S. epidermidis, Pseudomonas aeruginosa, Listeria monocytogenes) as a consequence of the accumulation of reactive oxygen species (ROS) that impair cellular metabolism and cause cellular death [23].

The mechanisms of known chemotherapeutic agents used against fungi (polyenes, nystatin, amphotericin B) are based on the disruption of structure of cellular membranes and the leak of the cellular content [24]. Our research has also found that REP at MFC and higher concentration causes leakage of genetic material from mycelium cells A. alternata. In the research of Saho et al. leakage of cells content of Botrytis cinerea as a result of treatment with a tea tree oil has been demonstrated [25]. While, Carvalho et al. [23] demonstrated that the mechanism of antagonistic action of gallic acid against Candida albicans could be based on interaction with ergosterol and tannins binding to that component of the cellular wall, and consequently disrupting the integrity of external membranes of fungal cells. That mechanism of action was confirmed by Campoy and Adrio [24]. Another mechanism, described by Ahmad et al. [26] and Li et al. [27], involves a possible inhibition of the activity of enzymes that are responsible for the synthesis of ergosterol in the fungal cell wall. The study by $\mathrm{Li}$ et al. [27] demonstrated that gallic acid inhibited activity of two enzymes, namely sterol $14 \alpha$-demethylase and squalene epoxidase, which are responsible for the synthesis of intracellular ergosterol in Tricophytom rubrum.

\section{Conclusion}

Our study indicates that the analyzed ellagitannin formula may be successfully used as a food preservative. It may be used as a natural addition to both processed and non-processed food, ensuring effective inhibition of the growth of Alternaria alternata. Inhibition of sporulation and increased membrane permeability are mechanisms of action of ellagitannin formula on Alternaria alternata. The current study may provide some underusing on the mechanisms of inhibition of growth of filamentous fungi by ellagitannins, including Sanguiin H5, H6 and H10, and Lambertianin C. Further studies will be carried out to gain a better insight in the topic.

Acknowledgements This work was supported by the National Science Centre (Grant number 2013/09/B/NZ9/01806).

\section{Compliance with ethical standards}

Conflict of interest There is no conflict of interests.

Compliance with ethics requirements This article does not contain any studies with human participants or animals performed by any of the authors.

Open Access This article is licensed under a Creative Commons Attribution 4.0 International License, which permits use, sharing, adaptation, distribution and reproduction in any medium or format, as long as you give appropriate credit to the original author(s) and the source, provide a link to the Creative Commons licence, and indicate if changes were made. The images or other third party material in this article are included in the article's Creative Commons licence, unless indicated otherwise in a credit line to the material. If material is not included in the article's Creative Commons licence and your intended use is not permitted by statutory regulation or exceeds the permitted use, you will need to obtain permission directly from the copyright holder. To view a copy of this licence, visit http://creativecommons.org/licenses/by/4.0/. 


\section{References}

1. Arcella D, Escola M, Ruiz JAG (2016) Dietary exposure assessment to Alternaria toxins in the European population. EFSA J 14(12):4654

2. Lee HB, Patriarca A, Magan N (2015) Erratum to Alternaria in Food: Ecophysiology, mycotoxin, production and toxicology [Mucobiology 43,2(2015): 93-106]. Mycobiology 43(3):371-371

3. Escrivá L, Oueslati S, Font G, Manyes L (2017) Alternaria mycotoxins in food and feed: an overview. J Food Qual. https://doi. org/10.1155/2017/1569748

4. Juan C, Oueslati S, Mañes J (2016) Evaluation of Alternaria mycotoxins in strawberries: quantification and storage condition. Food Addit Contam Part A Chem Anal Control Expo Risk Assess 33(5):861-868

5. Singh A, Abhishek KD, Singh VK, Upadhyay N, Chaudhari AK, Das S, Dubey NK (2019) Essential oils formulations as safe preservatives for stored plant masticatories against fungal and mycotoxin contamination: a review. Biocatal Agric Biotechnol $17: 313-317$

6. Gevrenova R, Badjakov I, Nikolova M, Doichinova I (2013) Phenolic derivatives in raspberry (Rubus L.) germplasm collection in Bulgaria. Biochem Syst Ecol 50:419-427

7. Zhang Y, Zhang Z, Yang Y, Zu X, Guan D, Wang Y (2011) Diuretic activity of Rubus idaeus L. (Rosaceae) in rats. Trop J Pharm Res 10(3):243-248

8. Aguilera-Carbo A, Augur Ch, Prado-Barragan LA, Favela-Torres E, Aguilar CN (2008) Microbial production of ellagic acid and biodegradation of ellagitannins. Appl Microbiol Biotechnol 78:189-199

9. Lipińska L, Klewicka E, Sójka M (2014) Structure, occurrence and biological activity of ellagitannins: a general review. Acta Sci Pol Technol Aliment 13(3):289-299

10. Gasperotti M, Masuero D, Vrhovsek U, Guella G, Mattivi F (2010) Profiling and accurate quantification of Rubus ellagitannins and ellagic acid conjugates using direct UPLC-Q-TOF HDMS and HPLC-DAD analysis. J Agric Food Chem 58:4602-4616

11. Nohynek LJ, Alakomi HL, Kähkönen MP, Heinonen M, Helander IM, Oksman-Caldentey KM, Puupponen-Pimiä RH (2006) Berry phenolics: antimicrobial properties and mechanisms of action against severe human pathogens. Nutr Cancer 54:18-32

12. Yoshida T, Hatano T, Ito H, Okuda T (2009) Structural diversity and antimicrobial activities of ellagitannins. In: Quideau S (ed) Chemistry and biology of ellagitannins: an underestimated class of bioactive plant polyphenols. World Scientific, Singapore, pp 55-93

13. Yamaguchi MU, Garcia FP, Cortez DAG, Ueda-Nakamura T, Filho BPD, Nakamura CV (2011) Antifungal effects of ellagitannin isolated from leaves of Ocotea odorifera (Lauraceae). Atonie Van Leuw 99:507-514

14. Ascacio-Valdés J, Burboa E, Aguilera-Carbo AF, Aparicio M, Pérez-Schmidt R, Rodríguez R, Aguilar CN (2013) Antifungal ellagitannin isolated from Euphorbia antisyphilitica Zucc. Asian Pac J Trop Biomed 3(1):41-46

15. Klewicka E, Sójka M, Klewicki R, Kołodziejczyk K, Lipińska L, Nowak A (2016) Ellagitannins from raspberry Rubus idaeus L. as natural inhibitors of Geotrichum candidum. Molecules 21(7):908
16. Gleń K, Boligłowa E (2011) The effect of PRP SOL fertilizer on the dynamics of phytopathogenic and antagonistic fungi growth in vitro. J Res Appl Agric Eng 56:97-101

17. Zhang X, Sun Y, Yang Q, Chen L, Li W, Zhang H (2015) Control of posthaverest black rot caused by Alternaria alternate in strawberries by the combinations of Cryptococcus laurentii and benzo-(1,2,3) thiadiazole-7-carbothioic acid $S$-methyl ester. Biol Control 90:96-101

18. Chen J, Zou X, Liu Q, Wang F, Feng W, Wan N (2014) Combination effect of chitosan and methyl jasmonate on controlling Alternaria alternata and enhancing activity of cherry tomato fruit defense mechanisms. Crop Prot 56:31-36

19. Dutreix L, Bernard C, Juin C, Imbert C, Girardot M (2018) Do raspberry extracts and fractions have antifungal or anti-adherent potential against Candida spp.? Int J Antimicrob Agents 52:947-953

20. Sales PM, Souza PM, Simeoni LA, Silveira D (2012) $\alpha$-Amylase inhibitors: a review of raw material and isolated compounds from plant source. J Pharm Pharm Sci 15:141-183

21. Engström MT, Pälijärvi M, Salminen JP (2015) Rapid fingerprint analysis of plant extracts for ellagitannins, gallic acid and quinic acid derivatives and quercetin-kaempferol- and myricetin-based flavonol glycosides by UPLC-QqQ-MS/MS. J Agric Food Chem 63:4068-4079

22. Simirgiotis MJ, Bórquez J, Schmeda-Hirschmann G (2013) Antioxidant capacity, polyphenolic content and tandem HPLCDAD-ESI/MS profiling of phenolic compounds from the South American berries Luma apiculata and L. chequén. Food Chem 139:289-299

23. Carvalho RS, Carollo CA, de Magalhães JC, Palumbo JMC, Boaretto AG, Nunes e Sá IC, Ferraz AC, Lima WG, de Siqueira JMS, Ferreira JMS (2018) Antibacterial and antifungal activities of phenolic compound-enriched ethyl acetate fraction from Cochlospermum regium (mart. Et. Schr.) Pilger roots: mechanisms of action and synergism with tannin and gallic acid. S Afr J Bot 114:181-187

24. Campoy S, Adrio JI (2017) Antifungals. Biochem Pharmacol 133:86-96

25. Shao X, Cheng S, Wang H, Yu D, Mungai C (2013) The possible mechanism of antifungal action of tea tree oil on Botrytis cinerea. J Appl Microbiol 114:1642-1649

26. Ahmad A, Wani MY, Khan A, Manzoor N, Molepo J (2015) Synergistic interactions of eugenol-tosylate and its congeners with fluconazole against Candida albicans. PLoS ONE 10:e145053

27. Li ZJ, Liu M, Dawuti G, Dou Q, Ma Y, Liu HG, Aibai S (2017) Antifungal activity of gallic acid in vitro and in vivo. Photother Res 19:1-7

Publisher's Note Springer Nature remains neutral with regard to jurisdictional claims in published maps and institutional affiliations. 